\title{
Non-adherence in type 2 diabetes: practical considerations for interpreting the literature
}

REVIEW

\author{
This article was published in the following Dove Press journal: \\ Patient Preference and Adherence \\ 2 March 2013 \\ Number of times this article has been viewed
}

\author{
David F Blackburn' \\ Jaris Swidrovich ${ }^{2}$ \\ Mark Lemstra' \\ 'College of Pharmacy and Nutrition, \\ University of Saskatchewan, \\ Saskatoon, Saskatchewan, ${ }^{2}$ Leslie Dan \\ Faculty of Pharmacy, University of \\ Toronto, Toronto, Ontario, Canada
}

Correspondence: David F Blackburn

College of Pharmacy and Nutrition,

I I 0 Science Place, Saskatoon,

Saskatchewan, Canada, S7N 5 C9

Tel + I 306966208 I

Fax + I 3069666377

Email d.blackburn@usask.ca

\begin{abstract}
The rising prevalence of type 2 diabetes poses a serious threat to human health and the viability of many health care systems around the world. Although several prescription medications can play a vital role in controlling symptoms and preventing complications, non-adherence to these therapies is highly prevalent and has been linked to increases in morbidity, mortality, and health care costs. Although a vast array of significant adherence predictors has been identified, the ability to explain or predict non-adherence with known risk-factors remains poor. Further, the definitions, outcomes, and various measures used in the non-adherence literature can be misleading for the unfamiliar reviewer. In this narrative review, a practical overview of important considerations for interpreting adherence endpoints and measures is discussed. Also, an organizational framework is proposed to consider published adherence interventions. This framework may allow for a unique appreciation into areas of limited knowledge and thus highlights targets for future research.
\end{abstract}

Keywords: medication adherence, compliance, type 2 diabetes, adherence interventions

\section{Introduction}

Type 2 diabetes mellitus is a metabolic disorder associated with elevations in blood glucose as well as other important risk factors such as blood pressure, cholesterol, and coagulation. ${ }^{1}$ The prevalence of this condition is high and it continues to climb, as a result of an aging population and rising obesity rates across the world. ${ }^{2}$ In fact, it is predicted that the global prevalence of diabetes will increase by $65 \%$ over the next 20 years. $^{2}$

Rising prevalence rates are a major concern for governments and health-insurance providers because patients with type 2 diabetes suffer from multiple comorbid conditions in far greater numbers than those without. Fortunately, outpatient management with several readily available medications such as glucose-lowering, cholesterol-lowering, and blood-pressure-lowering medications can significantly lower the risks for macrovascular and/or microvascular complications. ${ }^{1}$ As a result, these medications are recommended for concurrent use by typical patients, especially those with increasing age or multiple risk factors. ${ }^{1}$

Unfortunately, the requirement for multiple chronic medications is almost inextricably linked to problems with medication adherence. Indeed, among people with type 2 diabetes, the prevalence of non-adherence is high ${ }^{3-5}$ and appears to be an important cause of increased morbidity and mortality. ${ }^{6-11}$ Moreover, when all non-adherence related hospitalizations were identified in four US hospitals, diabetes was the second leading cause behind mental health conditions. ${ }^{12}$ Considering the 
consequences of non-adherence have been estimated at $\$ 100$ billion per year in the United States alone, ${ }^{13}$ it would appear that non-adherence in diabetes is an extremely costly problem. It has been estimated that increases in medication adherence of only $20 \%$ could reduce total health care spending by $\$ 1074$ for every person with diabetes. ${ }^{11}$ Unfortunately, it remains unclear whether adherence interventions can consistently improve adherence rates by this magnitude. Thus, the cost-effectiveness of adherenceenhancing interventions remains unknown. ${ }^{14}$

\section{Definition of non-adherence}

Over the years, several alternative terms have been proposed to describe medication non-adherence such as concordance, compliance, obedience, observance, conformity, acceptance, and persistence. ${ }^{15-17}$ The World Health Organization (WHO) defined adherence as "the extent to which a person's behavior - taking medication, following a diet, and/or executing lifestyle changes, corresponds with agreed recommendations from a health care provider." ${ }^{18}$ However, we believe medication adherence should be described simply as the extent to which individuals take medications that have known health benefits. This proposed definition avoids any reference to the origins of non-adherence and specifically represents the public health epidemic resulting from an underuse of potentially life-saving medications. In contrast, the WHO definition specifies a particular problem relating to an agreement between patient and provider when most studies are not able to determine whether such an agreement has ever occurred. ${ }^{3}$ As such, non-adherence needs to be identified and addressed in its entirety, without prior assumptions relating to cause or culprit.

\section{Non-adherence rates require careful interpretation}

The first year after starting a chronic medication poses the highest-risk for medication non-adherence for all types of chronic diseases. On average, $50 \%$ of new medication users will fail to consume at least $80 \%$ of prescribed doses during their first year of therapy. ${ }^{13,18,19}$ Rates of non-adherence to antidiabetic therapies appear to follow this general observation quite closely. However, research papers often cite wideranging estimates. A systematic review of anti-diabetic therapies found adherence rates between $36 \%$ to $93 \%{ }^{3}$

Several factors contribute to the wide variability in adherence rates observed in published studies. First, studies restricted to individuals starting new medications will almost always find lower adherence rates compared to studies where "experienced" users are included. This observation results from a consistently high rate of attrition observed in the first few months after starting any new medication. ${ }^{20,21}$ Second, adherence rates expressed as percentages can vary substantially depending on whether they are categorical percentages (ie, percent of a population achieving $\geq 80 \%$ adherence) or are mean percentages (mean percent adherence achieved in a population). When both measures are calculated on the same set of adherence data, categorical percentages will always be lower than mean percentages. For example, suppose a mean adherence rate of $70 \%$ is measured among a sample of medication users. It can be reasoned that approximately half of these individuals will have achieved an adherence level of $70 \%$ or higher (assuming the data is near-normally distributed). If only half of the subjects achieved $70 \%$ adherence, even fewer will have achieved $80 \%$ adherence (which is the conventional definition of categorical adherence). ${ }^{6,22}$ Thus, in our hypothetical cohort, adherence could be reported as a mean of $70 \%$ or a categorical percentage of $<50 \%$ (eg, 45\%), where both percentages accurately represent the exact same adherence level. Unfortunately, the specific type of adherence measure is not always clearly identified; thus, readers should be careful to avoid using these rates interchangeably.

Another important source of variability in reported adherence rates results from the many different methods of assessment. Quantitative measures are often derived from electronic refill records, electronic pill bottle monitors, self-reported visual analog scales, or manual pill counts. Alternatively, a number of different qualitative measures are also available. For example, non-adherence was defined as at least one positive response to any of the four item Morisky questions in a recent study by Lewis et al: (1) "Have you ever forgotten to take your blood pressure (BP) medicine?" (2) "Are you sometimes careless in regards to your medicine?" (3) "Do you skip your medicine when you are feeling well?" (4) "When you feel badly due to the medicine, do you skip it?". ${ }^{23,24}$ In another study investigating the validity of items in an adherence questionnaire, non-adherence was defined simply as self-reporting a missed dose in the previous week. $^{25}$

Reconciling the different measures and reported rates can be difficult because self-reported and quantitative adherence measures are not highly correlated ${ }^{26}$ and no single gold-standard approach is available. Self-reported measures are more easily implemented in clinical settings (ie, doctors' offices), ${ }^{27}$ but validity may be affected by social desirability bias in some individuals. ${ }^{28}$ In contrast, electronic 
refill records allow for efficient assessments of large study populations; however, the act of taking medications is not directly assessed by medication refills. Clearly, the type of adherence measure as well as the specific summary statistic used (mean versus categorical) can substantially contribute to variability in published adherence rates. Therefore, readers must take special care to evaluate these issues, especially in cases where adherence findings are unexpectedly high or low in any specific study.

\section{Patterns of non-adherence}

Non-adherence in the first year appears to be consistently driven by three unique patterns of medication use: (a) primary non-adherence, (b) non-persistence, and (c) noncompliance or poor execution. ${ }^{21,29}$ Primary non-adherence refers to patients who receive a prescription but never actually obtain the medication. Rates of primary non-adherence for anti-diabetic therapies have been reported between $4 \%$ and $31 \%$, even though troublesome symptoms would be expected for individuals who do not receive glucose-lowering medications. ${ }^{4,5,30}$

Non-persistence and poor execution are patterns of nonadherence that are demonstrated by patients who actually begin taking their medications. Those exhibiting nonpersistence stop taking their medication altogether, whereas poor executers continue taking prescribed medications but fail to consume the recommended quantity on a regular basis. ${ }^{31}$ Recent studies suggest that "early non-persistence," where individuals discontinue a medication soon after obtaining the first prescription, contributes disproportionately to overall non-adherence in the first year of therapy. ${ }^{5,21,32}$ For example, individuals who discontinue antihypertensive or statin medications within the first 3 months of therapy make up between $30 \%$ and $50 \%$ of all cases of non-adherence in the first year. ${ }^{21,32}$ Moreover, many of these individuals appear to quit after receiving the very first dispensation as evidenced by no further fills during a full year of follow up. ${ }^{21,32}$ These are important observations because both antihypertensives and statins have clear benefits in reducing major cardiovascular events in patients with type 2 diabetes. ${ }^{1}$

Understanding the various patterns of non-adherence is also important because widely acknowledged non-adherence factors such as forgetfulness or complexity may not be applicable to a high proportion of non-adherent patients who discontinue soon after the very first dispensation or for those who neglect to start taking a medication altogether., ${ }^{43,34}$ Correspondingly, certain adherence support strategies such as reminders ${ }^{35}$ or dosing organizers ${ }^{36}$ may be irrelevant for these patients. Interestingly, a significant body of research has been directed towards the barriers associated with initiation of insulin therapy in type 2 diabetics. ${ }^{37,38}$ Considering the high rates of primary non-adherence and early non-persistence observed with all glucose-lowering medications, perhaps greater preparation is required for patients starting any type of anti-diabetic therapy, not just insulin.

\section{Predictors of non-adherence}

Well recognized paradigms are available to help understand the vast array of possible barriers to achieving good adherence (Table 1). 13,18,39,40 Meichenbaum and Turk ${ }^{40}$ organized determinants of non-adherence into the following categories: (a) characteristics of the patient; (b) characteristics of the treatment regimen; (c) features of the disease; (d) prescriberlevel factors (including patient-physician relationship); and (e) the clinical setting. All evidence suggests the determinants of non-adherence in type- 2 diabetics are consistent with other chronic conditions, although some may argue that insulin use is associated with unique barriers because of its requirement for subcutaneous injection. ${ }^{37,38}$ Paradigms such as the one outlined above highlight the importance of external factors that shape a patient's interpretation of the appropriateness of any medication. In addition, the contribution of unwitting non-adherence cannot be overlooked as an important cause of non-adherence. ${ }^{41}$ Although unwitting non-adherence is often attributed to forgetfulness, it is highly likely that a substantial portion of non-persistent individuals simply do not understand their medications are supposed to be taken long-term.

Non-adherence is not considered to be a result of baseline personality type. ${ }^{40}$ Rather, models of health behavior ${ }^{18}$ and adherence behavior ${ }^{40}$ support the notion that non-adherence is often a result of external influences rather than baseline preferences. ${ }^{40,42}$ Although compelling anecdotes and personal experiences with "disobedient patients" are powerful influences to practicing health care professionals, these types of patients probably contribute only a small part to the overall problem of medication non-adherence. ${ }^{40}$ As a result, individual patient factors are known to contribute minimally (if at all) to the overall occurrence of non-adherence observed in population-based studies. ${ }^{42,43}$

The fact that currently known adherence predictors are only weakly associated with the development of non-adherence might be surprising considering the vast number of research articles published in this area. One possible explanation for the lack of clarity around adherence predictors arises from conventional approaches used to report their associations. 
Table I Theoretical frameworks of non-adherence

\begin{tabular}{|c|c|c|c|}
\hline World Health Organization ${ }^{18}$ & Osterberg and Blaschke ${ }^{13}$ & Balkrishnan $^{39}$ & $\begin{array}{l}\text { Meichenbaum } \\
\text { and Turk }{ }^{40}\end{array}$ \\
\hline Patient factors & Patient factors & Demographic variables & Patient factors \\
\hline \multirow[t]{3}{*}{ Social/economic factors } & & Patient's health-related knowledge & \\
\hline & & and beliefs & \\
\hline & & Economic variables & \\
\hline Condition related factors & & Medical variables & Disease factors \\
\hline Therapy related factors & & Medication related variables & Treatment factors \\
\hline Provider behaviors & Provider factors & Physician-patient interaction & $\begin{array}{l}\text { Relationship to } \\
\text { providers }\end{array}$ \\
\hline Health care system factors & Health care system factors & & Clinic organization \\
\hline
\end{tabular}

Specifically, many studies use odds ratios to represent the "risk" associated with adherence predictors; however, this measure can be misleading if it is considered equivalent to a relative-risk. To illustrate the difference, consider a retrospective study of subjects with heart failure where older age (ie, $\geq 65$ years) was a significant negative predictor of optimal adherence to beta-blockers. ${ }^{44}$ The percentage of older patients achieving optimal adherence was $66 \%(764 / 1165)$ while the corresponding percentage among those $<65$ years was $71 \%$ (177/249). Using a relative-risk calculation, the effect of old age can be expressed as 0.93 (66\%/71\%), corresponding to a $7 \%$ reduction in the occurrence of optimal adherence. In contrast, the same unadjusted effect expressed as an odds ratio equals $0.78(1.90 / 2.46)$, or a $22 \%$ reduction in the "odds" of optimal adherence. This example highlights a well-known limitation of odds ratios, namely they are a poor reflection of the relative risk when highly prevalent outcomes are examined. ${ }^{45}$ It should be recognized that non-adherence is a highly prevalent outcome in the vast majority of published studies (often between $40 \%$ to $60 \%$ ). As a result, the effect of any adherence predictor will almost always be overestimated if the odds ratio is interpreted as a relative-risk.

Not only are individual factors weakly predictive on their own, multivariable models do not predict or explain more than a fraction of the massive burden of non-adherence observed in population studies. ${ }^{42,43}$ For example, Wong et al could explain less than $4 \%$ of all cases of non-adherence (measured from prescription refill databases) using available patient-level and clinic-level factors from administrative data sources among 444,418 patients with diabetes registered in the National Veterans Affairs database in the US. ${ }^{43}$ However, one of the major limitations to these population-based studies is the inability to capture patient-specific factors such as attitudes, beliefs, and knowledge. In addition, it is possible that more eloquent representation of prescriber factors may help contribute to our understanding of the non-adherence phenomenon.
Factors relating to the prescriber cannot be overlooked as important determinants of non-adherence. ${ }^{33,42,46-51}$ Prescribers may influence adherence through simplifying dosing regimens or consolidating refills to keep patients organized. ${ }^{52}$ Also, certain prescribers might provide greater education and preparation prior to prescribing a new chronic medication. ${ }^{51}$ However, the specific nature of the association between prescriber and non-adherence has yet to be fully elucidated. Also, the extent to which these factors can be harnessed to optimize adherence remains unknown. Although prescriber-relation might substantially influence adherence, we believe that front-line physicians are largely unaware of their potential influence in this area. ${ }^{53}$

\section{Published adherence interventions}

The literature describes numerous strategies for addressing non-adherence in patients with type 2 diabetes as well as many other chronic conditions. However, no single or combined strategy has resulted in more than small to modest benefits in rigorous trials. ${ }^{14,54-60}$ Additionally, for every published successful intervention, it is often possible to identify one failed approach where very similar strategies were employed. This observation is very important to recognize because the literature is full of recommendations from well-respected organizations suggesting multifactorial, ${ }^{13,61}$ multidisciplinary, ${ }^{62}$ and patient-focused strategies. ${ }^{18,63}$ Although these recommendations have been developed by recognized experts making logical interpretations of available data, many of the published interventions are of poor quality and none have followed diabetic patients prospectively to determine if health outcomes are ultimately improved. ${ }^{14,64}$ In reality, much more research is needed before reliable adherence strategies can be recommended with a high level of certainty and generalizability.

It may be useful to organize adherence interventions by the source of the intervention (allied health care professional, 
prescriber, peer, institution/health system, or messagebased), the target of the intervention (allied health care professional, prescriber, patient, or institution/health system), or by the nature of the strategy (motivational/behavioral, cost, reminders, etc) (Figure 1). Using this framework, two important observations can be made about published adherence interventions in diabetes. First, allied health care professionals deliver the vast majority of published adherence interventions whereas prescriber-delivered interventions are infrequently attempted. ${ }^{14,60}$ For example, in a systematic review of adherence interventions targeting type 2 diabetics, none of the 21 eligible studies was delivered by prescribers. ${ }^{14}$ Second, adherence interventions overwhelmingly target patients directly, ${ }^{14,60,63,65}$ whereas few interventions focus on prescribers ${ }^{66}$ despite a significant body of research suggesting they play an important role. ${ }^{33,42,46-51}$

The strategies used to support medication adherence vary widely from reminder-based systems like text messaging to complex behavioral and chronic disease management approaches. Reminder type strategies such as text messaging have not consistently improved adherence or clinical markers such as hemoglobin $\mathrm{A}_{1 \mathrm{c}}{ }^{54,55,67}$ Similarly, complex, multifactorial interventions have not been consistently positive either. ${ }^{56,68}$ Among studies that have been successful, only modest benefits are typically observed and adherence improvements are frequently lost following completion of the study intervention. ${ }^{14,58}$

Interestingly, non-adherence cannot be prevented even if patient drug costs are completely eliminated. Choudhry et al examined the influence of eliminating drug costs for individuals discharged from the hospital. ${ }^{69}$ Although the study was not aimed at type 2 diabetics per se, the study population was made up of post-myocardial infarction patients where 35\% (2023/5855) had diabetes at baseline. Surprisingly, full-coverage for statins, angiotensinconverting enzyme inhibitors, angiotensin receptor blockers, and beta-blockers resulted in very little improvement to average adherence (38.9\% to $43.9 \%)$ over a median of 394 days. However, the occurrence of vascular events was significantly reduced by this intervention (hazard ratio for total major vascular events or revascularization $=0.89$; 95\% confidence interval $0.90-0.99 ; P=0.03$ ). These findings reinforce two major lessons regarding adherence interventions. First, medication adherence has many possible determinants ${ }^{40}$ so eliminating a single barrier, even something as important as cost, ${ }^{70}$ will not solve the problem. Second, small improvements to multiple medications may have substantial reductions in morbidity associated with chronic diseases.

\section{Where do we go from here?}

It has been clearly shown that none of our current strategies are very effective at reducing the occurrence of medication non-adherence. However, the intervention framework proposed herein outlines many areas for future research that have not been explored. For instance, it is not known if the success of a specific adherence intervention will vary depending on the person who delivers it. We could find only one prospectively designed intervention delivered directly by physicians. ${ }^{66}$ In this case, adherence was extremely high in both intervention and control groups, making it difficult to assess the performance of this strategy. In virtually all other studies, follow-up visits to improve adherence are carried out by allied health care professionals, often with little coordination to the actual prescribing physician. In addition, prescribers could be targets of adherence interventions whereby aggregate statistics of adherence could be regularly fed back to physicians for the purposes of monitoring overall success and following trends over time.

While we await future discoveries in this area of research, currently proposed recommendations by key organizations represent our best knowledge $\mathrm{e}^{13,18,62,63}$ and attempts should be made to raise awareness about medication non-adherence in all health care settings and empathize with the struggles of

\begin{tabular}{|c|c|c|}
\hline $\begin{array}{c}\text { Source of adherence } \\
\text { intervention }\end{array}$ & $\begin{array}{c}\text { Nature of adherence } \\
\text { intervention }\end{array}$ & $\begin{array}{l}\text { Target of adherence } \\
\text { intervention }\end{array}$ \\
\hline $\begin{aligned}> & \text { Allied health care } \\
& \text { provider } \\
> & \text { Professional } \\
> & \text { Prescriber } \\
> & \text { Peer } \\
> & \text { Institution } \\
> & \text { Health system } \\
> & \text { Message-based }\end{aligned}$ & $\begin{aligned} &> \text { Motivational } \\
& \text { interviewing } \\
&>\text { Behavioral } \\
& \text { intervention } \\
&>\text { Cost variation } \\
&>\text { Reminders } \\
&>\text { Follow-up } \\
&>\text { Education }\end{aligned}$ & $\begin{aligned} & \text { Allied health care } \\
& \text { provider } \\
> & \text { Prescriber } \\
> & \text { Non-adherent patient } \\
> & \text { Adherent/new patient } \\
> & \text { Institution } \\
> & \text { Health system }\end{aligned}$ \\
\hline
\end{tabular}

Figure I Proposed framework to classify adherence interventions. 
diabetic patients to embrace prescription medications as part of their daily lives.

\section{Disclosure}

David Blackburn and Mark Lemstra's positions at the University of Saskatchewan are funded through unrestricted financial support from AstraZeneca Canada, Merck Frosst Schering, Pfizer Canada, and the Saskatchewan Ministry of Health. None of these sponsors had input into the drafting or submission of this manuscript. The authors report no other conflicts of interest in this work.

\section{References}

1. American Diabetes Association. Standards of medical care in diabetes - 2010. Diabetes Care. 2010;33 Suppl 1:S11-S61.

2. Brunton S, Gough S, Hicks D, et al. A look into the future: improving diabetes care by 2015. Curr Med Res Opin. 2011;27 Suppl 3: $65-72$.

3. Cramer JA. A systematic review of adherence with medications for diabetes. Diabetes Care. 2004;27(5):1218-1224.

4. Fischer MA, Stedman MR, Lii J, et al. Primary medication non-adherence: analysis of 195,930 electronic prescriptions. J Gen Intern Med. 2010;25(4):284-290.

5. Karter AJ, Parker MM, Moffet HH, Ahmed AT, Schmittdiel JA, Selby JV. New prescription medication gaps: a comprehensive measure of adherence to new prescriptions. Health Serv Res. 2009;44(5 Pt 1):1640-1661.

6. Asche C, LaFleur J, Conner C. A review of diabetes treatment adherence and the association with clinical and economic outcomes. Clin Ther. 2011;33(1):74-109.

7. Hansen RA, Farley JF, Droege M, Maciejewski ML. A retrospective cohort study of economic outcomes and adherence to monotherapy with metformin, pioglitazone, or a sulfonylurea among patients with type 2 diabetes mellitus in the United States from 2003 to 2005. Clin Ther. 2010;32(7):1308-1319.

8. Pladevall M, Williams LK, Potts LA, Divine G, Xi H, Lafata JE. Clinical outcomes and adherence to medications measured by claims data in patients with diabetes. Diabetes Care. 2004;27(12):2800-2805.

9. Ho PM, Rumsfeld JS, Masoudi FA, et al. Effect of medication nonadherence on hospitalization and mortality among patients with diabetes mellitus. Arch Intern Med. 2006;166(17):1836-1841.

10. Donnelly LA, Morris AD, Evans JM; DARTS/MEMO collaboration. Adherence to insulin and its association with glycaemic control in patients with type 2 diabetes. QJM. 2007;100(6):345-350.

11. Sokol MC, McGuigan KA, Verbrugge RR, Epstein RS. Impact of medication adherence on hospitalization risk and healthcare cost. Med Care. 2005;43(6):521-530.

12. Senst BL, Achusim LE, Genest RP, et al. Practical approach to determining costs and frequency of adverse drug events in a health care network. Am J Health Syst Pharm. 2001;58(12):1126-1132.

13. Osterberg L, Blaschke T. Adherence to medication. $N$ Engl J Med. 2005;353(5):487-497.

14. Vermeire E, Wens J, Van Royen P, Biot Y, Hearnshaw H, Lindenmeyer A. Interventions for improving adherence to treatment recommendations in people with type 2 diabetes mellitus. Cochrane Database Syst Rev. 2005;2:CD003638.

15. Bissonnette JM. Adherence: a concept analysis. JAdv Nurs. 2008;63(6): 634-643.

16. Hobden A. Concordance: a widely used term, but what does it mean? Br J Community Nurs. 2006;11(6):257-260.

17. Barron TI, Bennett K, Feely J. A competing risks prescription refill model of compliance and persistence. Value Health. 2010;13(6):796-804.
18. World Health Organization. Adherence to Long-Term Therapies. Evidence for Action. Geneva: World Health Organization; 2003. Available from: http://whqlibdoc.who.int/publications/2003/9241545992.pdf. Accessed January 29, 2013.

19. Grégoire JP, Sirois C, Blanc G, Poirier P, Moisan J. Persistence patterns with oral antidiabetes drug treatment in newly treated patients - a population-based study. Value Health. 2010;13(6):820-828.

20. Blackburn D, Dobson R, Blackburn J, Wilson T, Stang MR, Semchuk W. Adherence to statins, beta-blockers and angiotensin-converting enzyme inhibitors following a first cardiovascular event: A retrospective cohort study. Can J Cardiol. 2005;21(6):485-488.

21. Evans CD, Eurich DT, Remillard AJ, Shevchuk YM, Blackburn DF. First-fill medication discontinuations and nonadherence to antihypertensive therapy: An observational study. $\mathrm{Am} J$ Hypertens. 2012;25(2):195-203.

22. Peterson AM, Nau DP, Cramer JA, Benner J, Gwadry-Sridhar F, Nichol M. A checklist for medication compliance and persistence studies using retrospective databases. Value Health. 2007;10(1): $3-12$.

23. Lewis LM, Schoenthaler AM, Ogedegbe G. Patient factors, but not provider and health care system factors, predict medication adherence in hypertensive black men. $J$ Clin Hypertens (Greenwich). 2012;14(4):250-255.

24. Morisky DE, Green LW, Levine DM. Concurrent and predictive validity of a self-reported measure of medication adherence. Med Care. 1986;24(1):67-74.

25. Hahn SR, Park J, Skinner EP, et al. Development of the ASK-20 adherence barrier survey. Curr Med Res Opin. 2008;24(7):2127-2138.

26. Garber MC, Nau DP, Erickson SR, Aikens JE, Lawrence JB. The concordance of self-report with other measures of medication adherence: a summary of the literature. Med Care. 2004;42(7):649-652.

27. Garfield S, Clifford S, Eliasson L, Barber N, Willson A. Suitability of measures of self-reported medication adherence for routine clinical use: a systematic review. BMC Med Res Methodol. 2011;11:149.

28. Nieuwkerk PT, de Boer-van der Kolk IM, Prins JM, Locadia M, Sprangers MA. Self-reported adherence is more predictive of virological treatment response among patients with a lower tendency towards socially desirable responding. Antivir Ther. 2010;15(6): 913-916.

29. Barron TI, Bennett K, Feely J. A competing risks prescription refill model of compliance and persistence. Value Health. 2010;13(6):796-804.

30. Shin J, McCombs J, Sanchez R, Udall M, Deminski M, Cheetham M. Primary Nonadherence to Medications in an Integrated Healthcare Setting. Am J Manag Care. 2012;18(8):426-434.

31. Vrijens B, Vincze G, Kristanto P, Urquhart J, Burnier M. Adherence to prescribed antihypertensive drug treatments: longitudinal study of electronically compiled dosing histories. BMJ. 2008;336(7653): 1114-1117.

32. Lemstra M, Blackburn DF. Nonadherence to statin therapy: discontinuation after a single fill. Can J Cardiol. 2012;28(5): 567-573.

33. Jackevicius CA, Li P, Tu JV. Prevalence, predictors, and outcomes of primary nonadherence after acute myocardial infarction. Circulation. 2008;117(8):1028-1036.

34. Raebel MA, Ellis JL, Carroll NM, et al. Characteristics of patients with primary non-adherence to medications for hypertension, diabetes, and lipid disorders. J Gen Intern Med. 2012;27(1):57-64.

35. Renders CM, Valk GD, Griffin SJ, Wagner EH, Eijk Van JT, Assendelft WJ. Interventions to improve the management of diabetes in primary care, outpatient, and community settings: a systematic review. Diabetes Care. 2001;24(10):1821-1833.

36. Lee JK, Grace KA, Taylor AJ. Effect of a pharmacy care program on medication adherence and persistence, blood pressure, and lowdensity lipoprotein cholesterol: a randomized controlled trial. JAMA. 2006;296(21):2563-2571.

37. Funnell MM. Overcoming barriers to the initiation of insulin therapy. Clinical Diabetes. 2007;25(1):36-38. 
38. Peyrot M, Rubin RR, Lauritzen T, et al. Resistance to insulin therapy among patients and providers: results of the cross-national Diabetes Attitudes, Wishes, and Needs (DAWN) study. Diabetes Care. 2005;28(11):2673-2679.

39. Balkrishnan R. Predictors of medication adherence in the elderly. Clin Ther. 1998;20(4):764-771.

40. Meichenbaum D, Turk DC. Facilitating Treatment Adherence. A Practitioners Guidebook. New York: Plenum Press; 1987.

41. Wroe AL. Intentional and unintentional nonadherence: a study of decision making. J Behav Med. 2002;25(4):355-372.

42. Vermeire E, Hearnshaw H, Royen PV, Denekens J. Patient adherence to treatment: three decades of research. A comprehensive review. J Clin Pharm Ther. 2001;26(5):331-342.

43. Wong ES, Piette JD, Liu C, et al. Measures of adherence to oral hypoglycemic agents at the primary care clinic level. Med Care. 2012;50(7):591-598.

44. Lamb D, Eurich D, McAlister F, et al. Changes in adherence to evidence-based medications in the first year after initial hospitalization for heart failure: observational cohort study from 1994 to 2003. Circ Cardiovasc Qual Outcomes. 2009;2(3):228-235.

45. Zhang J, Yu KF. What's the relative risk? A method of correcting the odds ratio in cohort studies of common outcomes. JAMA. 1998;280(19): 1690-1691.

46. Piette JD, Heisler M, Krein S, Kerr EA. The role of patient-physician trust in moderating medication nonadherence due to cost pressures. Arch Intern Med. 2005;165(15):1749-1755.

47. Pound P, Britten N, Morgan M, et al. Resisting medicines: a synthesis of qualitative studies of medicine taking. Soc Sci Med. 2005;61(1): 133-155.

48. Stavropoulou C. Non-adherence to medication and doctor-patient relationship: Evidence from a European survey. Patient Educ Couns. 2011;83(1):7-13.

49. DiMatteo MR, Sherbourne CD, Hays RD, et al. Physicians' characteristics influence patients' adherence to medical treatment: results from the Medical Outcomes Study. Health Psychol. 1993;12(2): 93-102.

50. Kim SS, Kaplowitz S, Johnston MV. The effects of physician empathy on patient satisfaction and compliance. Eval Health Prof. 2004;27(3):237-251.

51. Tamblyn R, Abrahamowicz M, Dauphinee D, et al. Influence of physicians' management and communication ability on patients' persistence with antihypertensive medication. Arch Int Med. 2010; 170(12):1064-1072.

52. Choudhry NK, Fischer MA, Avorn J, et al. The implications of therapeutic complexity on adherence to cardiovascular medications. Arch Intern Med. 2011;171(9):814-822.

53. Blackburn D. Medication adherence is not our problem? J Am Coll Cardiol. 2011;58(15):1641; author reply 1642.

54. Arora S, Peters A, Agy C, Menchine M. A mobile health intervention for inner city patients with poorly controlled diabetes: proof-ofconcept of the TExT-MED Program. Diabetes Technol Ther. 2012; 14(6):492-496.
55. Franklin V, Waller A, Pagliari C, Greene S. A randomized controlled trial of Sweet Talk, a text-messaging system to support young people with diabetes. Diabetic Med. 2006;23(12):1332-1338.

56. Heisler M, Hofer TP, Schmittdiel JA, et al. Improving blood pressure control through a clinical pharmacist outreach program in patients with diabetes mellitus in 2 high-performing health systems: The Adherence and Intensification of Medications Cluster Randomized, Controlled Pragmatic Trial. Circulation. 2012;125(23):2863-2872.

57. Kocarnik BM, Liu C, Wong ES, et al. Does the presence of a pharmacist in primary care clinics improve diabetes medication adherence? $B M C$ Health Serv Res. 2012;12:391.

58. Mehuys E, Van Bortel L, De Bolle L, et al. Effectiveness of a community pharmacist intervention in diabetes care: a randomized controlled trial. J Clin Pharm Ther. 2011;36(5):602-613.

59. Misono AS, Cutrona SL, Choudhry NK, et al. Healthcare Information Technology Interventions to Improve Cardiovasular and Diabetes Medication Adherence. Am J Manag Care. 2010;16(12 Suppl HIT): SP82-SP92.

60. Salema NM, Elliot RA, Glazebrook C. A systematic review of adherence-enhancing interventions in adolescents taking long-term medicines. J Adolescent Health. 2011;49(5):455-466.

61. Baroletti S, Dell'Orfano H. Medication adherence in cardiovascular disease. Circulation. 2010;121(12):1455-1458.

62. National Council on Patient Information and Education. Enhancing Prescription Medication Adherence: A National Action Plan. Rockville: National Council on Patient Information and Education; 2007. Available from: http://www.talkaboutrx.org/documents/enhancing_prescription medicine_adherence.pdf. Accessed January 29, 2013.

63. Rubin RR. Adherence to pharmacologic therapy in patients with type 2 diabetes mellitus. Am J Med. 2005;118 Suppl 5A:27S-34S.

64. Evans CD, Watson E, Eurich DT, et al. Diabetes and cardiovascular disease interventions by community pharmacists: a systematic review. Ann Pharmacother. 2011;45(5):615-628.

65. Odegard PS, Goo A, Hummel J, Williams KL, Gray SL. Caring for poorly controlled diabetes mellitus: a randomized pharmacist intervention. Ann Pharmacother. 2005;39(3):433-440.

66. Rubak S, Sandbæk A, Lauritzen T, Borch-Johnsen K, Christensen B. Effect of "motivational interviewing" on quality of care measures in screen detected type 2 diabetes patients: a one-year follow-up of an RCT, ADDITION Denmark. Scand J Prim Health Care. 2011;29(2):92-98.

67. Vervloet M, Dijk Lv, Santen-Reestman J, et al. SMS reminders improve adherence to oral medication in type 2 diabetes patients who are real time electronically monitored. Int J Med Inform. 2012;81(9):594-604.

68. American Pharmacists Association. DOTx. MED: Pharmacist-delivered interventions to improve care for patients with diabetes. J Am Pharm Assoc (2003). 2012;52(1):25-33.

69. Choudhry NK, Avorn J, Glynn RJ, et al. Full coverage for preventive medications after myocardial infarction. $N$ Engl J Med. 2011;365(22):2088-2097.

70. Law MR, Cheng L, Dhalla IA, Heard D, Morgan SG. The effect of cost on adherence to prescription medications in Canada. CMAJ. 2012;184(3):297-302.
Patient Preference and Adherence

\section{Publish your work in this journal}

Patient Preference and Adherence is an international, peer-reviewed, open access journal focusing on the growing importance of patient preference and adherence throughout the therapeutic continuum. Patient satisfaction, acceptability, quality of life, compliance, persistence and their role in developing new therapeutic modalities and compounds to

\section{Dovepress}

optimize clinical outcomes for existing disease states are major areas of interest. This journal has been accepted for indexing on PubMed Central. The manuscript management system is completely online and includes a very quick and fair peer-review system. Visit http://www.dovepress.com/ testimonials.php to read real quotes from published authors. 